\title{
Predictive value of pediatric thrombosis diagnoses in the Danish National Patient Registry
}

This article was published in the following Dove Press journal:

Clinical Epidemiology

2 June 2010

Number of times this article has been viewed

\author{
Ruta Tuckuviene' \\ Soeren Risom Kristensen' \\ Jon Helgestad ${ }^{2}$ \\ Anette Luther Christensen' \\ Soeren Paaske Johnsen ${ }^{3}$ \\ 'Department of Clinical Biochemistry, \\ Center for Cardiovascular Research, \\ ${ }^{2}$ Department of Pediatrics, \\ ${ }^{3}$ Department of Clinical Epidemiology, \\ Aarhus University Hospital, Aalborg \\ and Aarhus, Denmark
}

Correspondence: Ruta Tuckuviene Department of Clinical Biochemistry, Aalborg Hospital, Aarhus University Hospital, Hobrovej 18-22, 9000 Aalborg, Denmark

Tel +4599323309

Fax +45 9813 II96

Email rt@rn.dk

\begin{abstract}
Data on the validity of pediatric thrombosis diagnoses are missing. We aimed to examine the predictive value of a diagnosis of venous and arterial thrombosis using the Danish National Patient Registry (DNPR). We identified all first-time diagnoses among children and adolescents (aged 0-18 years) between 1994 and 2006 in DNPR. In total, 1138 potential cases of thrombosis were identified; the medical records were retrieved for $1112(97.7 \%)$ and the positive predictive value (PPV) computed. Overall, the diagnosis of thrombosis was verified in 598 of the 1112 cases, corresponding to a PPV of 53.7\% (95\% confidence interval [CI]: 50.8-56.7). Diagnoses from wards had the PPV of $62.5 \%$ (95\% CI: 59.4-65.6). The predictive value of a thrombosis diagnosis from wards was age-dependent, with a higher PPV $(77.4 \%$, 95\% CI: 68.7-84.7) in neonates (<28 days) and adolescents (15-18 years) $(68.2 \%$; $95 \% \mathrm{CI}$ : $63.2-72.5))$ than in children (28 days-14 years) (51.2\%; (95\% CI: 46.0-56.4)). The PPV of a thrombosis diagnosis was improved by restricting the analysis to diagnoses from wards, primary diagnoses, and admissions with a length of stay of three or more days. The results indicate that an interpretation of nonvalidated hospital discharge data for pediatric thrombosis in a registry like DNPR should be made with caution.
\end{abstract}

Keywords: pediatric thrombosis, discharge diagnosis, registry, positive predictive value

\section{Introduction}

Thromboembolic disease, including both arterial and venous thrombosis, is generally uncommon in children but impacts mortality, chronic morbidity, and childhood development. The incidence of pediatric thromboembolism seems to increase in parallel with diagnostic and therapeutic advances and decreased mortality in children with primary critical illnesses. ${ }^{1}$

Administrative databases and medical registries are often used in epidemiological research and access to such data sources is almost mandatory when conducting largescale epidemiological studies of rare diseases, including pediatric thromboembolism. However, all data, including data from registries, need to be valid in order to avoid misleading results. Validation studies of thrombosis diagnoses in children are lacking, though there are several studies on the quality of registry data for arterial ${ }^{2-13}$ and venous thromboembolism in adults. ${ }^{14-18}$ The aim of the present study was to determine the positive predictive value (PPV) of arterial and venous thrombosis diagnoses for 0 to 18-year-old individuals in the Danish National Patient Registry (DNPR).

\section{Material and methods}

The Danish National Health Service provides free, tax-supported health care to the entire population of Denmark. ${ }^{19}$ Information on discharges from Danish hospitals 
is available in the Danish National Patient Registry, which contains data on all discharges since 1977 and all outpatients since $1995 .{ }^{20}$ The data include the dates of admission and discharge, surgical procedure(s) performed, and up to 20 diagnoses classified according to the International Classification of Diseases (ICD; 8th revision until the end of 1993 and the 10th revision thereafter). Discharge diagnoses in the registry are determined exclusively by the physician, who discharges the patient.

All incident cases in children and adolescents with a firsttime discharge diagnosis of arterial and/or venous thrombosis were identified in the DNPR. We only included patients who were 0-18 years old and residents of Denmark at the time of admission. The study period was restricted to January 1, 1994 through December 31, 2006. The ICD-10 diagnosis codes of thrombosis and number of recorded diagnoses in the DNPR are presented in Table 1.

\section{Criteria for diagnoses}

A diagnosis of thrombosis was confirmed if documented by clinical presentation and supported by findings from imaging, surgery, or autopsy. The presence of clinical signs was mandatory for confirming a diagnosis. The detailed clinical presentation of thrombosis in different age groups was reported previously. ${ }^{21-23}$ We considered the following definitions of thrombosis:

Cerebral sinovenous thrombosis (CSVT): any transient neurological dysfunction and thrombosis of the cerebral veins or venous sinuses demonstrated by computed tomography
(CT), magnetic resonance (MR) scan, MR venography, and/ or conventional cerebral venography.

Pulmonary embolism (PE): dyspnea, chest pain, hypoxia, and cardiac-respiratory collapse combined with findings from ventilation-perfusion lung scan, CT, or pulmonary angiography.

Deep venous thrombosis (DVT): swelling, pain, and discoloration of the extremities or vena cava superior syndrome or renal and/or liver dysfunction, and ultrasonography ULS/venography/CT/MR findings in agreement with thrombosis.

Arterial ischemic stroke (AIS): clinical presentation consistent with stroke (ie, neurological deficits, seizures, lethargy, or abnormalities in muscle tone) and a CT scan or MR showing a focal ischemic infarct of a location and age consistent with the neurological signs and symptoms. Patients with primary cerebral hemorrhage not associated with AIS or CSVT were excluded.

Thrombosis in the arteries of limbs, abdomen, and thorax: ischemia of the limb or selected organ dysfunction supported by findings from contrast angiography/Doppler ultrasonography/CT/MR or surgery. Thrombosis in stents and arteriovenous grafts were not included.

Myocardial infarction (MI): symptoms supported by electrocardiogram (ECG) and biochemical markers or findings on coronary angiography.

Retinal occlusion: visual problems confirmed by ophthalmoscopic examination or by positive findings on angiography/CT/MR.

Table I ICD-10 diagnoses of thrombosis in children (0-18 years of age) recorded in the Danish National Patient Registry (DNPR) during the period 1994-2006

\begin{tabular}{|c|c|c|c|}
\hline Thrombosis localization & & ICD-I 0 diagnosis codes & $\begin{array}{l}\text { Number of first-time diagnoses } \\
\text { recorded in the DNPR } \mathrm{n}(\%)\end{array}$ \\
\hline \multirow[t]{6}{*}{ Venous } & Cerebral sinovenous & 167.6, 163.6, G0.8 & $57(5.0)$ \\
\hline & Retinal veins & $\mathrm{H} 34.8$ & $4(0.4)$ \\
\hline & Pulmonary embolism & 126 & $105(9.2)$ \\
\hline & $\begin{array}{l}\text { Vena cava, renal veins, } \\
\text { hepatoportal veins }\end{array}$ & $18 \mid-182$ & $103(9.1)$ \\
\hline & Deep veins of extremities & $180.1-180.9$ & 391 (34.4) \\
\hline & $\begin{array}{l}\text { Venous thrombosis in relation } \\
\text { to pregnancy }\end{array}$ & $\begin{array}{l}\text { O22.5A, O87.3, O22.3, } \\
\text { O22.8-9, O87A-F, O87.I }\end{array}$ & 0 \\
\hline \multirow[t]{5}{*}{ Arterial } & Ischemic stroke & $163-164$ & $364(32.0)$ \\
\hline & Retinal arteries & H34.I-H34.2 & $4(0.4)$ \\
\hline & $\begin{array}{l}\text { Arteries of extremities } \\
\text { and/or aorta }\end{array}$ & 174 & $6 \mathrm{I}(5.4)$ \\
\hline & Renal arteries & $\mathrm{N} 28.0 \mathrm{~A}, \mathrm{~N} 28.0 \mathrm{D}$ & 0 \\
\hline & Myocardial infarction & 121 & $42(3.7)$ \\
\hline Miscellaneous (combined & Mesenterial & $\mathrm{K} 55.0 \mathrm{H}, \mathrm{K} 55.0 \mathrm{C}$ & 0 \\
\hline arterial and venous) & Retinal & H34, H34.9 & $7(0.6)$ \\
\hline All & & & $1138(100)$ \\
\hline
\end{tabular}




\section{Medical record review}

Medical records were retrieved and reviewed by a single experienced pediatrician (RT) using a detailed standardized form developed in collaboration with local and international consultants in pediatric hematology/oncology with pediatric thrombosis experience. Cerebral and noncerebral thromboses were registered in separate forms, focusing on symptoms and date of symptoms, imaging, location of the thrombosis, dates of diagnosis and treatment, possible causes of not confirming the diagnosis in DNPR, choice and effect of treatment, risk factors and outcome (Appendices A, B). The review was based on all available information in the medical records, including results from laboratory tests (coronary biomarkers), ECG, and radiology reports. The actual imaging films were not re-interpreted, and the assessment was based on written reports by a radiologist. The reviewer was not blinded to the registered discharge codes.

\section{Ethics}

The study was approved by the Danish Data Protection Agency (J. no. 2007-41-0539) and the National Board of Health (J. no. 7-604-04-2/37/EHE).

\section{Statistical analysis}

The PPV of the thrombosis diagnoses recorded in the DNPR was calculated as a proportion; the numerator was the number of patients with a confirmed diagnosis after a review of the medical records and the denominator was the total number of patients registered with a specific diagnosis. The PPV was calculated for all patients and separately for neonates ( $<28$ days old) including preterm born neonates ( $<$ gestational week $37+0)$, children (28 days-14 years old), adolescents (15-18 years old), and specific diagnostic categories. Preterm born children aged 28 days -14 years at the time of thrombosis were attributed to the age group "children". Data were also stratified by sex, type of hospital department (emergency room or ward, including outpatient clinic), length of stay (shorter vs 3 days or longer), type of diagnosis (primary or secondary), type of hospital (university vs regional), and calendar periods (1994-1999, 1999-2002, and 2003-2006). The estimation of $95 \%$ confidence intervals (CI) was based on an approximation of the PPV to binomial distribution. Data were analyzed using STATA statistical software version 10.

\section{Results}

\section{Thrombosis diagnoses in the DNPR}

A total of 1138 individuals aged $0-18$ years residing in Denmark were recorded with a first-time diagnosis of thrombosis in the DNPR during the period 1994-2006 (Table 1). We were able to retrieve and review medical records from $1112(97.7 \%)$ of these patients.

\section{Diagnostic tools for diagnosing thrombosis}

Diagnostic tools used to confirm different types of thrombosis are presented in Table 2. MR imaging was used to confirm CSVT diagnosis in $84.2 \%$ of CSVT cases and AIS in $68.9 \%$ of AIS cases. The remaining cerebral thromboses were documented by CT. Ultrasonography was used to evaluate 214 of 259 patients $(82.6 \%$ ) with verified diagnoses of DVT, whereas contrast angiography alone was used in 30 of 259 cases (11.6\%; Table 2). Findings from coronary angiography

Table 2 Diagnostic tools for verified diagnosis of symptomatic thrombosis

\begin{tabular}{|c|c|c|c|c|c|c|c|}
\hline \multirow{2}{*}{$\begin{array}{l}\text { Diagnostic } \\
\text { method }\end{array}$} & \multicolumn{3}{|c|}{ Venous thrombosis } & \multicolumn{3}{|c|}{ Arterial thrombosis } & \multirow{2}{*}{$\begin{array}{l}\text { Retinal } \\
\text { occlusion } \\
\mathrm{n}=\mathbf{3} \\
\mathrm{n}(\%)\end{array}$} \\
\hline & $\begin{array}{l}\text { CSVT } \\
n=38 \\
n(\%)\end{array}$ & $\begin{array}{l}\text { DVT }^{b} \\
n=259 \\
n(\%)\end{array}$ & $\begin{array}{l}\text { PE } \\
n=48 \\
n(\%)\end{array}$ & $\begin{array}{l}\text { AIS }^{c} \\
n=209 \\
n(\%)\end{array}$ & $\begin{array}{l}\text { Extremities/aorta } \\
n=37 \\
n(\%)\end{array}$ & $\begin{array}{l}\text { MI } \\
n=4 \\
n(\%)\end{array}$ & \\
\hline$M R( \pm C T)$ & $32(84.2)$ & $9(3.5)$ & I (2.I) & $144(68.9)$ & $2(5.4)$ & - & - \\
\hline CT alone & $6(16.2)$ & $9(3.5)$ & $10(20.8)$ & $64(30.3)$ & $2(5.4)$ & - & - \\
\hline $\begin{array}{l}\text { Ultrasonography } \\
\text { ( } \pm \text { other tools) }\end{array}$ & - & $214(82.6)$ & - & - & I4 (37.8) & - & - \\
\hline $\begin{array}{l}\text { Ventilation-perfusion } \\
\text { lung scan ( } \pm \text { other tools) }\end{array}$ & - & - & $34(70.8)$ & - & - & - & - \\
\hline Angiography alone & - & $30(1 \mathrm{l} .6)$ & $I(2 . I)$ & - & $13(35.1)$ & $2(50.0)$ & I (33.3) \\
\hline Autopsy & - & - & $I(2 . I)$ & - & - & I $(25.0)$ & - \\
\hline Miscellaneous ${ }^{\mathrm{a}}$ & - & - & $I(2.1)$ & - & $8(21.6)^{d}$ & I (25.0) & $2(66.7)$ \\
\hline
\end{tabular}

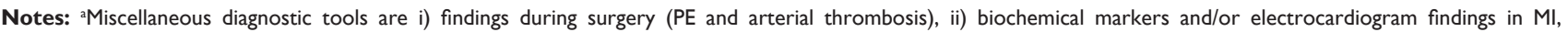
iii) ophthalmoscopic examination in retinal occlusion. bMethod of examination was unknown in one patient with DVT in the extremities and abdomen. ${ }^{c}$ Type of brain scan was unknown in one patient with AIS. 'Two newborns were included based on clinical signs of a threatened limb. Imaging or surgery was not performed.

Abbreviations: AIS, arterial ischemic stroke; CT, computed tomography; CSVT, cerebral sinovenous thrombosis; DVT, deep venous thrombosis; MI, myocardial infarction; $M R$, magnetic resonance; $P E$, pulmonary embolism. 
supported the diagnosis of MI in two patients, whereas typical changes in ECG were seen in one MI case and autopsy findings confirmed the diagnosis in a fourth child.

\section{Positive predictive values}

A thrombosis diagnosis was confirmed in 598 of 1112 patients, corresponding to an overall PPV of $53.7 \%(95 \%$ confidence interval [CI]: 50.8-56.7). When diagnoses recorded in emergency departments were excluded $(n=176)$, the PPV increased 62.5\% (95\% CI: 59.4-65.6) (Table 3). All diagnoses in neonates were made at wards, while 44 of 419 children and 132 of 578 adolescents had diagnoses from emergency departments. The PPV of diagnoses among adolescents and children was 54.7\% (95\% CI: 50.5-58.8) and 46.1\% (95\% CI: 41.2-51.0), respectively, and increased substantially among adolescents when emergency room diagnoses were excluded (Table 3). Focusing at diagnoses from wards, no major differences in PPV between the diagnostic categories was found, except for diagnosis of MI (Table 3). Variation in the PPV was seen in some specific thrombosis diagnoses from wards between the three age groups (Table 3 ). Predictive values of a thrombosis diagnosis from wards were age-dependent, with the highest PPV in neonates, and the PPV in adolescents higher than in children. The PPV among children were lower for venous thromboses and tended to be higher for AIS than in adolescents (Table 3).

The PPV of diagnoses from wards also differed according to length of hospital stay (shorter vs 3 days or longer), and to type of diagnosis (primary vs secondary) (Table 4). In contrast, no differences in the PPV were found according to gender, different study periods or type of hospital (university vs regional) (Table 4).

Almost half of the identified thrombosis diagnoses (514/1112) in the DNPR were not confirmed after the validation process. The main cause $(67.9 \%)$ for not being confirmed was the absence of findings consistent with thrombosis on imaging

Table 3 The positive predictive value (PPV) of arterial and venous thrombosis diagnoses in patients aged 0-18 years in the Danish National Patient Registry

\begin{tabular}{|c|c|c|c|c|c|c|}
\hline \multirow[t]{3}{*}{ Diagnoses } & \multicolumn{6}{|c|}{ PPV\% $(95 \% \mathrm{Cl})^{\mathrm{a}}, \mathrm{n}_{\text {confirmed }} / \mathbf{n}_{\text {total }} \mathrm{b}$} \\
\hline & \multirow[t]{2}{*}{ All departments } & \multirow{2}{*}{$\begin{array}{l}\text { Emergency } \\
\text { departments }\end{array}$} & \multicolumn{4}{|l|}{ Wards } \\
\hline & & & Total & $\begin{array}{l}\text { Neonates } \\
\text { ( }<28 \text { days) }\end{array}$ & $\begin{array}{l}\text { Children } \\
\text { (28 days-14 years) }\end{array}$ & $\begin{array}{l}\text { Adolescents } \\
\text { (15-18 years) }\end{array}$ \\
\hline \multirow[t]{2}{*}{ Total } & $53.7(50.8-56.7)$ & $7.4(|3.5-1| .3)$ & $62.5(59.4-65.6)$ & $77.4(68.7-84.7)$ & $51.2(46.0-56.4)$ & $68.2(63.6-72.5)$ \\
\hline & $598 / 1112$ & $13 / 176$ & $585 / 936$ & $89 / 115$ & $192 / 375$ & $304 / 446$ \\
\hline All venous & $53.9(50.0-57.8)$ & $7.4(3.6-13.2)$ & $66.3(62.0-70.5)$ & $82.4(65.5-93.2)$ & $39.0(30.4-48.2)$ & $74.4(69.5-78.9)$ \\
\hline thrombosis $^{c}$ & $345 / 640$ & $10 / 135$ & $335 / 505$ & $28 / 34$ & $48 / 123$ & $259 / 348$ \\
\hline \multirow[t]{2}{*}{ CSVT } & $66.7(52.9-78.6)$ & $0 / 2$ & $69.1(55.2-80.9)$ & $87.5(47.4-99.7)$ & $50.0(29.1-70.9)$ & $82.6(6 \mid .2-95.1)$ \\
\hline & $38 / 57$ & & $38 / 55$ & $7 / 8$ & $12 / 24$ & $19 / 23$ \\
\hline \multirow[t]{2}{*}{ PE } & $47.5(37.5-57.7)$ & $0 / 25$ & $63.2(51.3-73.9)$ & $0 / 1$ & $16.7(2.1-48.4)$ & $73.0(60.4-83.4)$ \\
\hline & $48 / 101$ & & $48 / 76$ & & $2 / 12$ & $46 / 63$ \\
\hline Thrombosis of & $62.8(52.6-72.1)$ & $9.1(0.3-4 I .3)$ & $69.2(58.7-78.7)$ & 94.7 (74.0-99.9) & $52.8(35.5-69.6)$ & $72.2(54.8-85.8)$ \\
\hline $\begin{array}{l}\text { vena cava, renal } \\
\text { veins, hepatoportal } \\
\text { veins }\end{array}$ & $64 / 102$ & $\mathrm{I} / \mathrm{II}$ & $63 / 91$ & $18 / 19$ & $19 / 36$ & $26 / 36$ \\
\hline \multirow[t]{2}{*}{ DVT in extremities } & $51.3(46.2-56.5)$ & $9.3(4.3-16-9)$ & $65.7(59.9-7 \mid .2)$ & $50.0(11.8-88.2)$ & $29.4(17.5-43.8)$ & $74.3(68.1-79.9)$ \\
\hline & $195 / 380$ & $9 / 97$ & $186 / 283$ & $3 / 6$ & $|5 / 5|$ & $168 / 226$ \\
\hline All arterial & $53.6(49.0-58.2)$ & $7.3(15.4-19.9)$ & $58.0(53.2-62.7)$ & $75.3(64.5-84.2)$ & $57.1(50.8-63.3)$ & $45.9(35.8-56.3)$ \\
\hline thrombosis $^{d}$ & $253 / 472$ & $3 / 41$ & $250 / 431$ & $61 / 81$ & $144 / 252$ & $45 / 98$ \\
\hline \multirow[t]{2}{*}{ AIS } & $58.1(52.8-63.2)$ & $4.6(1.2-22.8)$ & $61.5(56.1-66.8)$ & $73.9(61.5-84.0)$ & $62.3(55.3-68.9)$ & $47.0(34.6-59.7)$ \\
\hline & $209 / 360$ & $\mathrm{I} / 22$ & $208 / 338$ & $48 / 65$ & $129 / 207$ & $31 / 66$ \\
\hline Thrombosis in & $62.7(49.2-75.0)$ & $25.0(0.6-80.6)$ & $65.5(5 \mathrm{I} .4-77.8)$ & 92.3 (64.0-99.8) & $59.1(36.4-79.3)$ & $55.0(31.5-76.9)$ \\
\hline $\begin{array}{l}\text { arteries of the } \\
\text { extremities, aorta }\end{array}$ & $37 / 59$ & $1 / 4$ & $36 / 55$ & $12 / 13$ & $13 / 22$ & $11 / 20$ \\
\hline Myocardial & $10.5(2.9-24.8)$ & $7.7(0.2-36.0)$ & $\mid 2.0(2.6-3 \mid .2)$ & $50.0(1.3-98.7)$ & $12.5(1.6-38.4)$ & $0 / 7$ \\
\hline infarction & $4 / 38$ & $1 / 13$ & $3 / 25$ & $1 / 2$ & $2 / 16$ & \\
\hline \multirow[t]{2}{*}{ Retinal occlusions ${ }^{e}$} & $20.0(4.3-48.1)$ & $0 / 2$ & $23.1(5.0-53.8)$ & $0 / 1$ & $0 / 7$ & $60.0(14.7-94.7)$ \\
\hline & $3 / 15$ & & $3 / 13$ & & & $3 / 5$ \\
\hline
\end{tabular}

Notes: ${ }^{9} 95 \%$ confidence interval. b Number of confirmed diagnoses/number of recorded diagnoses. Including cerebral sinovenous thrombosis (CSVT), pulmonary embolism (PE), and deep venous thrombosis (DVT) in the extremities and miscellaneous veins. Including arterial ischemic stroke (AIS), thrombosis in the arteries of limbs and aorta, myocardial infarction (MI), and retinal occlusions. ${ }^{e}$ One arterial, one venous, one bland.

Abbreviation: $\mathrm{Cl}$, confidence interval. 
Table 4 The positive predictive value (PPV) of discharge diagnoses of venous and arterial thrombosis in the subgroup of in-patients (0-18 years) in the Danish National Patient Registry (DNPR)

\begin{tabular}{lll}
\hline Subgroups & $\mathbf{n}$ & PPV\% (95\% CI) \\
\hline Male & 400 & $62.5(57.6-67.3)$ \\
Female & 536 & $62.5(58.3-66.6)$ \\
Primary diagnosis & 615 & $66.8(63.0-70.5)$ \\
Secondary diagnosis & 321 & $54.2(48.6-59.8)$ \\
Hospital stay $<3$ days & 334 & $44.6(39.2-50.1)$ \\
Hospital stay $\geq 3$ days & 602 & $72.4(68.7-76.0)$ \\
University hospitals & 354 & $64.4(59.2-69.4)$ \\
Regional hospitals & 582 & $61.3(57.3-65.3)$ \\
Study periods: & & \\
1994-1998 & 321 & $61.4(55.8-66.7)$ \\
1999-2002 & 278 & $63.0(57.0-68.6)$ \\
2003-2006 & 337 & $63.2(57.8-68.4)$ \\
\hline
\end{tabular}

Abbreviations: $\mathrm{n}$, recorded diagnoses in DNPR; $\mathrm{Cl}$, confidence interval.

tests or a lack of imaging required to support the diagnosis of thrombosis (Table 5). An imaging test was not performed in 94 of 380 patients registered with a discharge diagnosis of DVT in the extremities and in 36 of 101 recorded PE diagnoses. Imaging confirmed primary cerebral hemorrhage was found in $7.5 \%$ of the patients registered with a diagnosis of AIS. Coding errors, defined as inaccuracies in coding the discharge diagnosis or incorrect data entry into a registry, were seen overall in $20.6 \%$ of possible thrombosis diagnoses. An accidental incorrect data entry was particularly frequent for rare diagnoses in children, specifically MI, retinal occlusion, and CSVT (Table 5).

\section{Discussion}

We found that only $53.7 \%$ of all pediatric thrombosis diagnoses registered in the DNPR could be confirmed after a review of the medical records. However, the registry also includes diagnoses from emergency rooms, and stratification by hospital departments increased the overall PPV, in particular the PPV among adolescents. The highest predictive values were associated with discharge diagnosis from a ward, primary diagnoses, a hospital stay of three or more days, and diagnoses made in neonates and adolescents.

To the best of our knowledge, the present study is the first to evaluate the quality of pediatric thrombosis diagnoses in an administrative registry. In adults, a PPV of $74 \%-84 \%$ has been reported for $\mathrm{VTE}^{14,16,17}$ and $65 \%-97 \%$ for arterial thromboembolism, including ischemic stroke 2-4,6,7,13,24 and coronary disease. ${ }^{8-12}$ The PPV of VTE diagnosis has also been examined in cohorts of women in relation to pregnancy, reporting predictive values of $80 \% .^{16,18}$ These validation studies are essential in epidemiological and clinical studies of thrombosis; however, the results can not be

Table 5 Unconfirmed thrombosis diagnoses

\begin{tabular}{|c|c|c|c|c|c|}
\hline \multirow{2}{*}{$\begin{array}{l}\text { Registered thrombosis } \\
\text { diagnosis }\end{array}$} & \multicolumn{5}{|c|}{ Unconfirmed diagnoses } \\
\hline & $\begin{array}{l}\text { Total } \\
\mathbf{n}\end{array}$ & $\begin{array}{l}\text { Asymptomatic } \\
\text { course } \\
\text { n (\%) }\end{array}$ & $\begin{array}{l}\text { Lack of confirmation } \\
\text { from imaging } \\
n(\%)\end{array}$ & $\begin{array}{l}\text { Incorrect code } \\
\text { n (\%) }\end{array}$ & $\begin{array}{l}\text { Miscellaneous }^{a} \\
\text { n (\%) }\end{array}$ \\
\hline $\begin{array}{l}\text { CSVT } \\
n=57\end{array}$ & 19 & 0 & $7(36.8)$ & $9(47.4)$ & $3(15.8)$ \\
\hline $\begin{array}{l}P E \\
n=|0|\end{array}$ & 53 & $2(3.8)$ & $4 \mathrm{I}(77.4)$ & $8(15.1)$ & $2(3.8)$ \\
\hline $\begin{array}{l}\text { Thrombosis of vena cava, } \\
\text { renal veins, hepatoportal } \\
\text { veins } \\
\mathrm{n}=102\end{array}$ & 38 & $6(15.8)$ & $20(52.6)$ & $8(2 I . I)$ & $4(10.6)$ \\
\hline $\begin{array}{l}\text { DVT in extremities } \\
\mathrm{n}=380\end{array}$ & 185 & I (0.5) & 157 (84.9) & $26(14.1)$ & $\mathrm{I}(0.5)$ \\
\hline $\begin{array}{l}\text { AIS } \\
n=360\end{array}$ & $15 \mid$ & $6(4.0)$ & $102(67.6)$ & $23(15.2)$ & $20(13.3)$ \\
\hline $\begin{array}{l}\text { Thrombosis in arteries } \\
\text { of the extremities, aorta } \\
n=59\end{array}$ & 22 & $\mathrm{I}(4.6)$ & $14(63.6)$ & $4(\mid 8.2)$ & $3(13.6)$ \\
\hline $\mathrm{MI} n=38$ & 34 & 0 & $6(17.7)$ & $19(55.9)$ & $9(26.5)$ \\
\hline Retinal occlusions $n=15$ & 12 & $\mathrm{I}(8.3)$ & $2(16.7)$ & $8(66.7)$ & $\mathrm{I}(8.3)$ \\
\hline $\begin{array}{l}\text { Total } \\
\mathrm{n}=1112\end{array}$ & 514 & $17(3.3)$ & $349(67.9)$ & $105(20.4)$ & $43(8.4)$ \\
\hline
\end{tabular}

Notes: Miscellaneous causes for exclusion: i) diagnosis before or after study period, ii) thrombosis in stents ( $\mathrm{n}=2$ arterial noncerebral), iii) diagnosis of thrombosis due to meningococcal infection ( $\mathrm{n}=\mathrm{I}$ arterial noncerebral), iv) lack of supporting ophthalmoscopic findings in retinal occlusions and biochemical markers and/or electrocardiogram findings in MI.

Abbreviations: AIS, arterial ischemic stroke; CSVT, cerebral sinovenous thrombosis; DVT, deep venous thrombosis; MI, myocardial infarction; PE, pulmonary embolism. 
extrapolated to thrombosis studies in children. The epidemiology and pathophysiology of thromboembolic disease in children is vastly different from what is seen in adults. Differences in the coagulation system during childhood and a constellation of endogenous and exogenous thrombophilic risk factors in children make pediatric thrombosis unique. In particular, neonates should be considered a separate population, different from older children, and several thromboembolic diseases, such as ischemic arterial stroke, are not comparable to AIS in adults. ${ }^{25}$ Therefore, results from studies in adults can not be generalized to studies of thrombosis in children.

A few studies have examined the quality of pediatric diagnoses in administrative databases. Diagnoses in children in the DNPR were examined in 1995 as a whole (no specification of diseases) and the PPV found to be $73.3 \% .^{20}$ Recently, pediatric diagnoses of asthma and febrile seizures in the DNPR were described to have high predictive values of $85.0 \%$ and $92.8 \%$, respectively. ${ }^{26,27}$ Furthermore, the PPV of childhood cancer diagnoses was estimated to be $97.1 \%$ in the nationwide Danish Cancer Registry. ${ }^{28}$ In contrast, the overall PPV of diagnoses of thrombosis from wards in our study was much lower, only $62.5 \%$. Thus, the diagnoses of thromboembolic diseases in the registry are more uncertain than diagnoses of cancer, febrile seizures, and asthma. However, the PPV of more homogenous groups and specific diagnoses in certain age groups (eg, VTE and CSVT in newborns with a PPV of $82.4 \%$ ) were comparable to the other validation studies of pediatric diagnoses.

The population in our study was divided into three groups: neonates ( $<28$ days), children (28 days-14 years), and adolescents (15-18 years). The relatively high PPV of diagnoses in newborns probably reflects their treatment in subspecialized neonatal divisions of pediatric departments. Children younger than 15 years of age are normally admitted directly to the pediatric departments in the hospitals taking care of all acute admissions, whereas adolescents older than 15 years of age are administratively assigned to adult wards. Emergency room diagnoses represent mostly "suspected" diagnoses, whereas the subsequent diagnostic steps and treatment are performed in the ward. We found a PPV of $7.4 \%$ for pediatric thrombosis diagnoses from emergency rooms. A low predictive value of thrombosis diagnoses from emergency rooms has also been reported among adults. ${ }^{3,11,17}$ A variation of $2.5 \%-90 \%$ in the agreement between diagnosis groups from clinical and administrative data sources has been found in pediatric emergency departments. ${ }^{29}$ However, thrombosis diagnoses were not among the diagnoses in that study. To the best of our knowledge, the low validity of emergency room diagnoses of pediatric thrombosis was not reported previously, and the findings might be important when conducting further studies.

Generally, there was no disagreement between the diagnosis in the medical records and the conclusion of our record review. The most common cause of nonconfirmed diagnoses was situations when suspicion of thrombosis was raised, but the diagnosis was ruled out by the objective examination or by imaging. In such situations, a code "observation for thrombosis" is supposed to be used but was not. Thus, the major cause of nonconfirmed diagnoses was incorrect coding rather than incorrect diagnostic work-up and diagnosis.

A wide range of medical conditions was identified among the cases where cerebral thrombosis could not be verified, including hypoxic-ischemic encephalopathy due to perinatal asphyxia, Todd's paralysis, intracerebral hemorrhage, migraine, and severe headache. Few patients with a diagnosis of arterial ischemic stroke had thrombosis in cerebral veins. When noncerebral thrombosis was ruled out, no alternative diagnosis could be made in the majority of cases. In some cases, however, a different diagnosis was made by the physician, such as rupture of muscle fiber or superficial thrombophlebitis instead of DVT, and muscle pain or hyperventilation rather than $\mathrm{PE}$.

The quality of data from administrative registries can be affected by errors in the data set. In our study, incorrect data entry was seen according to individual diagnosis codes in the DNPR and found in half of the recorded diagnoses of AMI ("I21" instead of "Q21" for congenital heart disease) and retinal occlusion ("H34" instead of "B34" for unspecific virus infection).

\section{Strengths and limitations}

Our study has the strength that it is based on the whole population in a country; thus, the findings are representative of the nationwide registry. The estimated incidence of symptomatic VTE and AIS in children is 0.07/10,000 and 0.1/10,000 person years, respectively. ${ }^{30,31}$ Thus, only large multi-center studies or population-based studies are able to assemble the epidemiological data required for the interpretation of the results. Our study was based on all first-time diagnoses of thrombosis in 0-18-year-old individuals over 13 years in a country with 5.5 million inhabitants. ${ }^{32}$ All residents have a unique personal registration number, which ensured a valid linking of information between the DNPR and medical records. Diagnoses in the registry were according to ICD-10, and all possible thrombosis diagnoses were identified in the examination in order to not miss 
any cases of thrombosis in the DNPR; for example, additional diagnoses of thrombosis in relation to pregnancy in teenage girls were included in the search, but none were found. The retrieval of medical records for possible thrombosis diagnoses was nearly complete; only 26 of 1138 records could not be found. The confirmation of thrombosis diagnosis was based on available information in the medical records, which may not be a perfect gold standard; however, we found the clinical information to be detailed and properly documented.

However, there are also some limitations to our study. Finding a thrombus in the imaging results without any symptoms (screening) was not considered a criterion for the verification of a diagnosis in our study. Overall, $1.5 \%$ of identified diagnoses (17/1112) were found to be asymptomatic. Additionally, two children had thrombi in stents and were not included in the analysis. These factors reduced the calculated PPV, but only to a minimal degree.

All records were reviewed by the same person. Therefore, the decisions are consistent, but they also rely on the judgment of this person. However, the forms that were used to make the judgments were developed in collaboration with other experienced clinicians, and all uncertain cases were discussed.

In our study we have not been able to asses the sensitivity, completeness and negative predictive value of DNPR because we had no method to track cases not registered in the DNPR. The vast majority of pediatric patients with such a severe disease are likely to be hospitalized, however, thrombosis diagnoses may be missed in the DNPR if the thrombosis is not considered to be a secondary diagnosis in a severe course of a complex disease (eg, pediatric cancer). An independent data source (eg, a pediatric thrombosis registry) would be needed in order to get further insights into the accuracy of the DNPR.

In conclusion, the overall positive predictive values of pediatric thrombosis diagnoses were low to moderate. The PPV might be improved by restricting the data to diagnoses from wards, patients with primary diagnoses, and admissions with a length of stay of 3 days or more. Thus, the use and interpretation of nonvalidated data on pediatric thromboembolism from the DNPR should only be done with caution.

\section{Disclosure}

The authors report no conflicts of interest in their work.

\section{References}

1. Raffini L, Huang YS, Witmer C, Feudtner C. Dramatic increase in venous thromboembolism in children's hospitals in the United States from 2001 to 2007. Pediatrics. 2009;124(4):1001-1008.

2. Ellekjaer H, Holmen J, Kruger O, Terent A. Identification of incident stroke in Norway: hospital discharge data compared with a populationbased stroke register. Stroke. 1999;30(1):56-60.
3. Johnsen SP, Overvad K, Sorensen HT, Tjonneland A, Husted SE Predictive value of stroke and transient ischemic attack discharge diagnoses in The Danish National Registry of Patients. J Clin Epidemiol. 2002;55(6):602-607.

4. Krarup LH, Boysen G, Janjua H, Prescott E, Truelsen T. Validity of stroke diagnoses in a National Register of Patients. Neuroepidemiology. 2007;28(3):150-154.

5. Roumie CL, Mitchel E, Gideon PS, Varas-Lorenzo C, Castellsague J, Griffin MR. Validation of ICD-9 codes with a high positive predictive value for incident strokes resulting in hospitalization using Medicaid health data. Pharmacoepidemiol Drug Saf. 2008;17(1):20-26.

6. Tirschwell DL, Longstreth WT Jr. Validating administrative data in stroke research. Stroke. 2002;33(10):2465-2470.

7. Tolonen H, Salomaa V, Torppa J, et al. The validation of the Finnish Hospital Discharge Register and Causes of Death Register data on stroke diagnoses. Eur J Cardiovasc Prev Rehabil. 2007;14(3):380-385.

8. Mahonen M, Salomaa V, Brommels M, et al. The validity of hospital discharge register data on coronary heart disease in Finland. Eur $J$ Epidemiol. 1997;13(4):403-415.

9. Madsen M, Davidsen M, Rasmussen S, Abildstrom SZ, Osler M. The validity of the diagnosis of acute myocardial infarction in routine statistics: a comparison of mortality and hospital discharge data with the Danish MONICA registry. J Clin Epidemiol. 2003;56(2): 124-130.

10. Pajunen P, Koukkunen H, Ketonen M, et al. The validity of the Finnish Hospital Discharge Register and Causes of Death Register data on coronary heart disease. Eur J Cardiovasc Prev Rehabil. 2005;12(2): 132-137.

11. Joensen AM, Jensen MK, Overvad K, et al. Predictive values of acute coronary syndrome discharge diagnoses differed in the Danish National Patient Registry. J Clin Epidemiol. 2009;62(2):188-194.

12. Merry AH, Boer JM, Schouten LJ, et al. Validity of coronary heart diseases and heart failure based on hospital discharge and mortality data in the Netherlands using the cardiovascular registry Maastricht cohort study. Eur J Epidemiol. 2009;24(5):237-247.

13. Rinaldi R, Vignatelli L, Galeotti M, Azzimondi G, de Carolis P. Accuracy of ICD-9 codes in identifying ischemic stroke in the General Hospital of Lugo di Romagna (Italy). Neurol Sci. 2003;24(2):65-69.

14. Lawrenson R, Todd JC, Leydon GM, Williams TJ, Farmer RD. Validation of the diagnosis of venous thromboembolism in general practice database studies. Br J Clin Pharmacol. 2000;49(6):591-596.

15. Arnason T, Wells PS, van Walraven C, Forster AJ. Accuracy of coding for possible warfarin complications in hospital discharge abstracts. Thromb Res. 2006;118(2):253-262.

16. Larsen TB, Johnsen SP, Moller CI, Larsen H, Sorensen HT. A review of medical records and discharge summary data found moderate to high predictive values of discharge diagnoses of venous thromboembolism during pregnancy and postpartum. J Clin Epidemiol. 2005;58(3):316-319.

17. Severinsen MT, Kristensen SR, Overvad K, Dethlefsen C, Tjonneland A, Johnsen SP. Venous thromboembolism discharge diagnoses in the Danish National Patient Registry should be used with caution. J Clin Epidemiol. 2009.

18. White RH, Brickner LA, Scannell KA. ICD-9-CM codes poorly indentified venous thromboembolism during pregnancy. J Clin Epidemiol. 2004;57(9):985-988.

19. Ministry of the Interior and Social Affairs. Health Care in Denmark. http://www.ism.dk/ Web site. Updated 2010. Accessed January 20, 2010.

20. Andersen TF, Madsen M, Jorgensen J, Mellemkjoer L, Olsen JH. The Danish National Hospital Register. A valuable source of data for modern health sciences. Dan Med Bull. 1999;46(3):263-268.

21. Chan AK, Deveber G, Monagle P, Brooker LA, Massicotte PM. Venous thrombosis in children. J Thromb Haemost. 2003;1(7):1443-1455.

22. Amlie-Lefond C, Sebire G, Fullerton HJ. Recent developments in childhood arterial ischaemic stroke. Lancet Neurol. 2008;7(5): 425-435.

23. Price VE, Chan AK. Arterial thrombosis in children. Expert Rev Cardiovasc Ther. 2008;6(3):419-428. 
24. Roumie CL, Mitchel E, Gideon PS, Varas-Lorenzo C, Castellsague J, Griffin MR. Validation of ICD-9 codes with a high positive predictive value for incident strokes resulting in hospitalization using Medicaid health data. Pharmacoepidemiol Drug Saf. 2008;17(1):20-26.

25. Massicotte MP, Sofronas M, deVeber G. Difficulties in performing clinical trials of antithrombotic therapy in neonates and children. Thromb Res. 2006;118(1):153-163.

26. Moth G, Vedsted P, Schiotz PO. National registry diagnoses agree with medical records on hospitalized asthmatic children. Acta Paediatr. 2007;96(10):1470-1473.

27. Vestergaard M, Obel C, Henriksen TB, et al. The Danish National Hospital Register is a valuable study base for epidemiologic research in febrile seizures. J Clin Epidemiol. 2006;59(1):61-66.

28. Wogelius P, Skriver MV, Sorensen HT. Predictive value of childhood cancer diagnoses in the Danish Cancer Registry. J Pediatr Hematol Oncol. 2004;26(11):701-702.
29. Gorelick MH, Knight S, Alessandrini EA, et al. Lack of agreement in pediatric emergency department discharge diagnoses from clinical and administrative data sources. Acad Emerg Med. 2007;14(7):646-652.

30. Andrew M, David M, Adams M, et al. Venous thromboembolic complications (VTE) in children: first analyses of the Canadian Registry of VTE. Blood. 1994;83(5):1251-1257.

31. Fullerton HJ, Wu YW, Zhao S, Johnston SC. Risk of stroke in children: ethnic and gender disparities. Neurology. 2003;61(2):189-194.

32. Statistics Denmark-statbank.dk. http://www.statistikbanken.dk/Web site. Updated 2010. Accessed January 20, 2010. 


\section{Appendix A}

\section{Cerebral thrombosis in children}

Date of collection:

Hospital:

Department:

Patient ID number:

1. Symptoms: $\square$ yes $\square$ no $\square$ unknown

$\square$ seizures $\square$ n.facialis paresis

$\square$ altered mental status $\square$ hemiparesis

$\square$ other

Date of start of symptoms: ............................. $\square$ unknown

2. Imaging performed: $\square$ yes $\square$ no $\square$ unknown
$\mathrm{CT} \pm$ angio confirming thrombosis: $\square$ yes $\square$ no $\square$ unknown
$\mathrm{MR} \pm$ angio confirming thrombosis: $\square$ yes $\square$ no $\square$ unknown $\square$ other confirming thrombosis: $\square$ yes $\square$ no $\square$ unknown

3. Pt. included: $\square$ yes $\square$ no

If not, cause: $\square$ no symptoms $\square$ no radiologic findings $\square$ error in coding $\square$ other

\section{Location of thrombosis i CNS: \\ $\square$ arterial $\square$ right side \\ $\square$ venous $\square$ left side}

Arterial CNS thrombosis:

$\square$ a. cerebri media $\square$ a. basilaris

$\square$ a. vertebralis $\square$ other

\section{Venous CNS thrombosis:}

$\square$ sinus sagitalis superior $\square$ internal veins

$\square$ sinus transversus $\square$ other

Presence of simultaneous hemorrhage: $\square$ yes $\square$ no $\square$ unknown

\section{Date of diagnosis of thrombosis: ...................... $\square$ unknown}

6. Antithrombotic treatment: $\square$ yes $\square$ no $\square$ unknown

\section{$\square$ LMWH}

Medication: unknown

Dose/kg/day: unknown

Date of start: .............................. $\square$ unknown

Date of completion: ................................ $\square$ no $\square$ unknown

\section{UFH}

Dose/kg/day: unknown

Date of start:
... .../....... $\square$ unknown 
Date of completion:

$$
\text { no } \square \text { unknown }
$$

\section{Aspirin}

Dose/kg/day: ... $/ \ldots \ldots \ldots . \ldots \ldots \ldots \ldots \ldots \ldots \ldots \ldots, \square$ unknown

Date of start:

Date of completion: ........................ $\square$ no $\square$ unknown

\section{Warfarin}

Date of start: ............................. $\square$ unknown

Date of completion: .............................. $\square$ no $\square$ unknown

\section{Other}

Medication: unknown

Date of start:

Date of completion: $. . / \ldots \ldots . . . . . \ldots \ldots \ldots . ., \square$ unknown ./..................... $\square$ no $\square$ unknown

7. Monitoring of LMWH treatment by P-antifactor Xa

yes $\square$ no $\square$ unknown

8. Bleeding during antithrombotic treatment: $\square$ yes $\square$ no $\square$ unknown

Location: ....................................... $\square$ unknown

Immediate intervention needed: $\square$ yes $\square$ no $\square$ unknown

Blood transfusion needed due to bleeding during antithrombotic treatment: $\square$ yes $\square$ no $\square$ unknown

9. Other complications to antithrombotic treatment: $\square$ yes $\square$ no $\square$ unknown

If yes, describe:

10. SVT resolution examined: $\square$ yes $\square$ no $\square$ unknown

If yes,

$\square$ CT \pm angio

$\mathrm{MR} \pm$ angio

SVT resolution: $. . . \ldots \ldots . . . \ldots \ldots . / \ldots \ldots \ldots \ldots . \square$ yes $\square$ no

completely $\square$ partial $\square$ unknown

11. Neurological sequelae after 1 year ( \pm 3 months): $\square$ yes $\square$ no $\square$ unknown

$\square$ epilepsy $\square$ motor impairment/disability $\square$ cognitive problems

$\square$ other:

\section{Risk factors}

12. Did pt. experience thrombosis before: $\square$ yes $\square$ no $\square$ unknown

If yes, date of 1. thrombosis: ........................ $\square$ unknown

Location of 1. thrombosis: ............................................ $\square$ unknown

Prophylactic antithrombotic treatment after 1. thrombosis: $\square$ yes $\square$ no $\square$ unknown

If yes, medication:

Completed: $\square$ yes $\square$ no $\square$ unknown

If yes, date of completion:

unknown 


\section{Disposition:}

Parents or siblings with thrombosis: $\square$ yes $\square$ no $\square$ unknown

Documented inherited thrombophilia in parents or siblings: $\square$ yes $\square$ no $\square$ unknown

If yes, describe:

14. Underlying cancer: $\square$ yes $\square$ no $\square$ unknown

If yes, diagnosis: $\square$ leukemia/lymphoma $\square$ CNS tumor $\square$ other

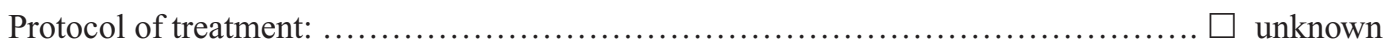

Phase of treatment during thrombosis: ...................................... $\square$ unknown

Treatment with asparaginase by the occurrence of thrombosis: $\square$ yes $\square$ no $\square$ unknown

Last dose of asparaginase before thrombosis: ....................... $\square$ unknown

Type of asparaginase:

$\square$ Erwinase $\square$ E. coli asparaginase $\square$ PEG asparaginase $\square$ unknown

Asparaginase stopped/dose decreased due to thrombosis? $\square$ yes $\square$ no $\square$ unknown

\section{Treatment by occurrence of thrombosis:}

Steroids: $\square$ yes $\square$ no $\square$ unknown

( $\square$ prednisolone $\square$ prednisone $\square$ dexamethasone $\square$ other)

TPN: $\square$ yes $\square$ no $\square$ unknown

Oral contraceptive: $\square$ yes $\square$ no $\square$ unknown

16. Varicella infection before AIS: $\square$ yes $\square$ no $\square$ unknown

If yes, date: ....................... $\square$ unknown

17. Infection by the time of admission: $\square$ yes $\square$ no $\square$ unknown

Type: .............................................. $\square$ unknown

Antibiotic treatment: $\square$ yes $\square$ no $\square$ unknown

Fever $>37.5$ : $\square$ yes $\square$ no $\square$ unknown

18. CVL: $\square$ yes $\square$ no $\square$ unknown

Date of the last insertion: ..................................................... $\square$ unknown

Type: $\square$ subcutane port $\square$ extern tunneled $\square$ extern untunneled $\square$ unknown

Location: $\square$ yes $\square$ unknown

If yes,

$\square$ right-sided $\square \mathrm{OE}$

$\square$ left-sided $\square$ UE

Vein: $\square$ unknown

CVL removed: $\square$ yes $\square$ no $\square$ unknown

Cause:

$\square$ thrombosis $\square$ infection $\quad \square$ other 
19. Arterial catheter: $\square$ yes $\square$ no $\square$ unknown

Date of insertion: ................................. $\square$ unknown

Artery: ......................................... $\square$ unknown

20.

\begin{tabular}{|l|c|c|c|}
\hline Risk factors within 3 months & yes & no & unknown \\
\hline Surgery & & & \\
\hline Immobilization ( $\geq 4$ days) & & & \\
\hline Trauma & & & \\
\hline
\end{tabular}

21. Other underlying diseases: $\square$ yes $\square$ no $\square$ unknown

If yes, describe:

22. Thrombophilia:

No work-up: $\square$ yes $\rightarrow$ end of scheme

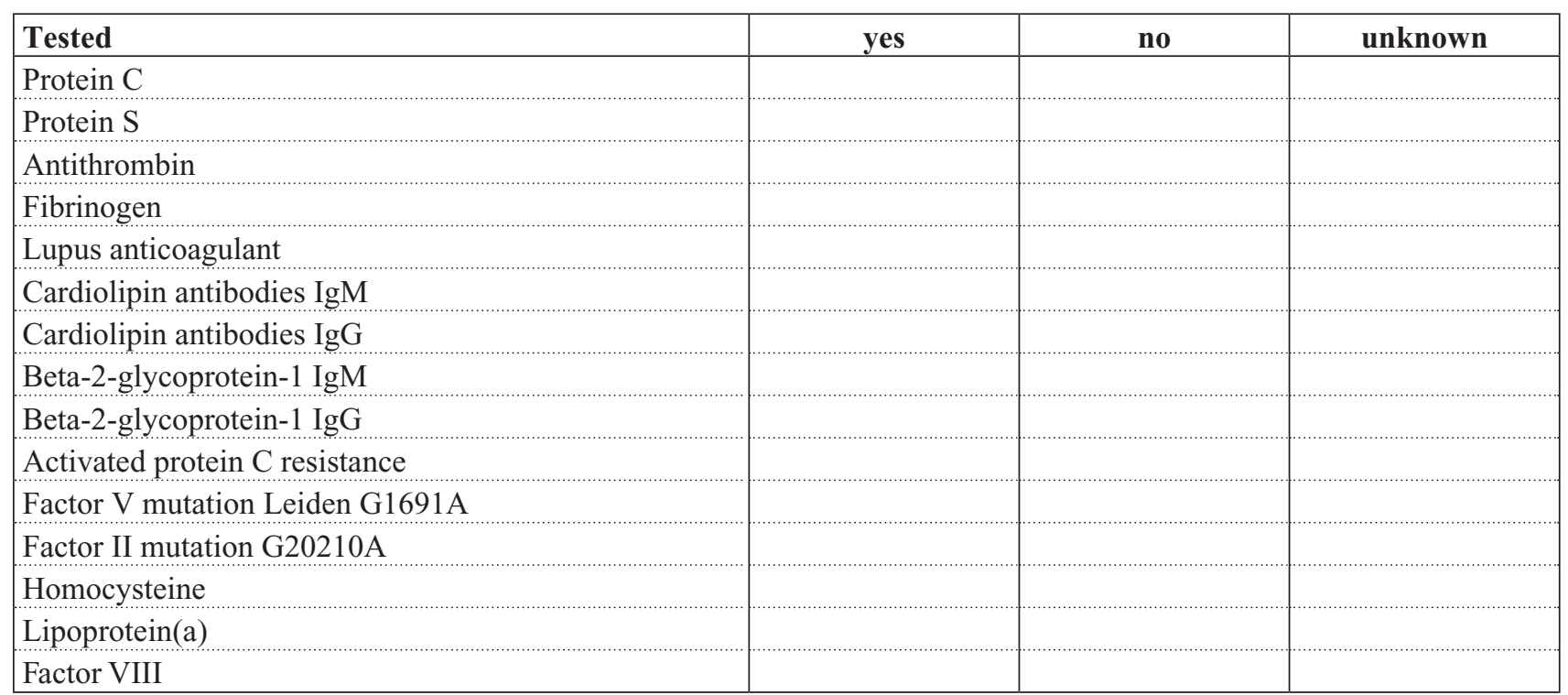

Documented defect: $\square$ yes $\square$ no $\square$ unknown

If yes, describe: 


\section{Appendix B}

\section{Noncerebral thrombosis in children}

Date of collection:

Hospital:

Department:

Patient ID number:

1. Symptoms: $\square$ yes $\square$ no $\square$ unknown

Date of start of symptoms: ./............ $\square$ unknown

2. Imaging performed: $\square$ yes $\square$ no $\square$ unknown

ULS \pm Doppler

Contrast veno/arteriography

$\mathrm{CT} \pm$ angio

$\mathrm{MR} \pm$ angio confirming thrombosis: $\square$ yes $\square$ no $\square$ unknown confirming thrombosis: $\square$ yes $\square$ no $\square$ unknown confirming thrombosis: $\square$ yes $\square$ no $\square$ unknown confirming thrombosis: $\square$ yes $\square$ no $\square$ unknown

3. Pt. included: $\square$ yes $\square$ no

If no, reason: $\square$ no symptoms $\square$ no radiologic findings $\square$ error in coding $\square$ other

\section{Location of thrombosis:}

Venous thrombosis: $\square$ yes

DVT in UE $\square$ v. cava inferior $\square$ v. cava superior

v. iliaca $\square$ v. lienalis $\square$ intracard right

v. femoralis $\square$ v. portae $\square$ v. subclavia

v. mesenterica $\square$ v. hepatica $\square$ v. jugularis

v. renalis $\square \mathrm{PE}$

other

Arterial thrombosis: $\square$ yes
a. femoralis $\square$ a. mesenterica $\square$ intracard left
a. iliaca $\square$ a. renalis $\square$ a. retinae
$\square$ aorta abdominalis $\square$ a. hepatica $\square$ a. brachialis

$\square$ other

Side: $\square$ yes $\square$ no $\square$ unknown

If yes,

$\square$ right

$\square$ left

5. Date of diagnosis: ........................ $\square$ unknown

6. Antithrombotic treatment: $\square$ yes $\square$ no $\square$ unknown

\section{LMWH}

Medication: unknown

Dose/kg/day: unknown

Date of start: ................................ $\square$ unknown

Date of completion ................................. $\square$ no $\square$ unknown 


\section{UFH}

Dose $/ \mathrm{kg} /$ day: .............................. $\square$ unknown

Date of start: ............................... $\square$ unknown

Date of completion ................................ $\square$ no $\square$ unknown

\section{$\square$ Aspirin}

Dose/kg/day: ................................ $\square$ unknown

Date of start: ................................ $\square$ unknown

Date of completion ............................... $\square$ no $\square$ unknown

\section{Warfarin}

Date of start: .............................. $\square$ unknown

Date of completion ................................ $\square$ no $\square$ unknown

\section{Other}

Medication: unknown

Date of start: ................................ $\square$ unknown

Date of completion .............................. $\square$ no $\square$ unknown

7. Monitoring of LMWH treatment by P-antifactor Xa

yes $\square$ no $\square$ unknown

8. Embolectomy: $\square$ yes $\square$ no $\square$ unknown

9. Bleeding during antithrombotic treatment: $\square$ yes $\square$ no $\square$ unknown

Location: ........................................... $\square$ unknown

Immediate intervention needed: $\square$ yes $\square$ no $\square$ unknown

Blood transfusion needed due to bleeding during antithrombotic treatment: $\square$ yes $\square$ no $\square$ unknown

10. Other complications of antithrombotic treatment: $\square$ yes $\square$ no $\square$ unknown

If yes, describe:

11. Resolution examined: $\square$ yes $\square$ no $\square$ unknown

ULS \pm Doppler

$\square$ contrast venography

$\mathrm{MR} \pm$ angio

$\mathrm{CT} \pm$ angio

Resolution confirmed: no $\square$ unknown

completely $\square$ partial $\square$ unknown

12. Sequelae after 1 year ( $\pm \mathbf{3}$ months): $\square$ yes $\square$ no $\square$ unknown

If yes, describe

\section{Risk Factors}

13. Did pt. experience thrombosis before: $\square$ yes $\square$ no $\square$ unknown

If yes, date of 1 . thrombosis: ........................... $\square$ unknown

Location of 1. thrombosis: .................................................... $\square$ unknown

Prophylactic antithrombotic treatment after 1. thrombosis: $\square$ yes $\square$ no $\square$ unknown 
If yes, medication:

Completed: $\square$ yes $\square$ no $\square$ unknown

If yes, date of completion: ................................................... $\square$ unknown

\section{Disposition:}

Parents or siblings with thrombosis: $\square$ yes $\square$ no $\square$ unknown

Documented inherited thrombophilia in parents or siblings: $\square$ yes $\square$ no $\square$ unknown

If yes, what:

15. Underlying cancer: $\square$ yes $\square$ no $\square$ unknown

If yes, diagnosis: $\square$ leukemia/lymphoma $\square$ CNS tumor $\square$ other

Protocol of treatment: ............................................................ $\square$ unknown

Phase of treatment during thrombosis: .................................... $\square$ unknown

Treatment with asparaginase by the occurrence of thrombosis: $\square$ yes $\square$ no $\square$ unknown

Last dose of asparaginase before thrombosis: ...................... $\square$ unknown

Type of asparaginase:

$\square$ Erwinase $\square$ E. coli asparaginase $\square$ PEG asparaginase $\square$ unknown

Asparaginase stopped/decreased dose due to thrombosis? $\square$ yes $\square$ no $\square$ unknown

\section{Treatment by occurrence of thrombosis:}

Steroids: $\square$ yes $\square$ no $\square$ unknown

( $\square$ prednisolone $\square$ prednisone $\square$ dexamethasone $\square$ other)

TPN: $\square$ yes $\square$ no $\square$ unknown

Oral contraceptive: $\square$ yes $\square$ no $\square$ unknown

17. Infection by the time of admission: $\square$ yes $\square$ no $\square$ unknown

Type: ............................................ $\square$ unknown

Antibiotic treatment: $\square$ yes $\square$ no $\square$ unknown

Fever >37.5: $\square$ yes $\square$ no $\square$ unknown

18. CVL: $\square$ yes $\square$ no $\square$ unknown

Date of the last insertion: ........................................................ $\square$ unknown

Type: $\square$ subcutane port $\square$ extern tunneled $\square$ extern untunneled $\square$ unknown

Location: $\square$ yes $\square$ unknown

If yes,

$\square$ right-sided $\square \mathrm{OE}$

$\square$ left-sided $\square$ UE

Vein:

$\square$ unknown

CVL removed: $\square$ yes $\square$ no $\square$ unknown

Cause:

$\square$ thrombosis $\square$ infection $\square$ other 
19. Arterial catheter: $\square$ yes $\square$ no $\square$ unknown

Date of insertion: .. $\square$ unknown

Artery:

unknown

20.

\begin{tabular}{|l|c|c|c|}
\hline Risk factors within 3 months & yes & no & unknown \\
\hline Surgery & & & \\
\hline Immobilization ( $\geq 4$ days) & & & \\
\hline Trauma & & & \\
\hline
\end{tabular}

21. Other underlying diseases: $\square$ yes $\square$ no $\square$ unknown

If yes, describe:

\section{Thrombophilia:}

No work-up: $\square$ yes $\rightarrow$ end of scheme

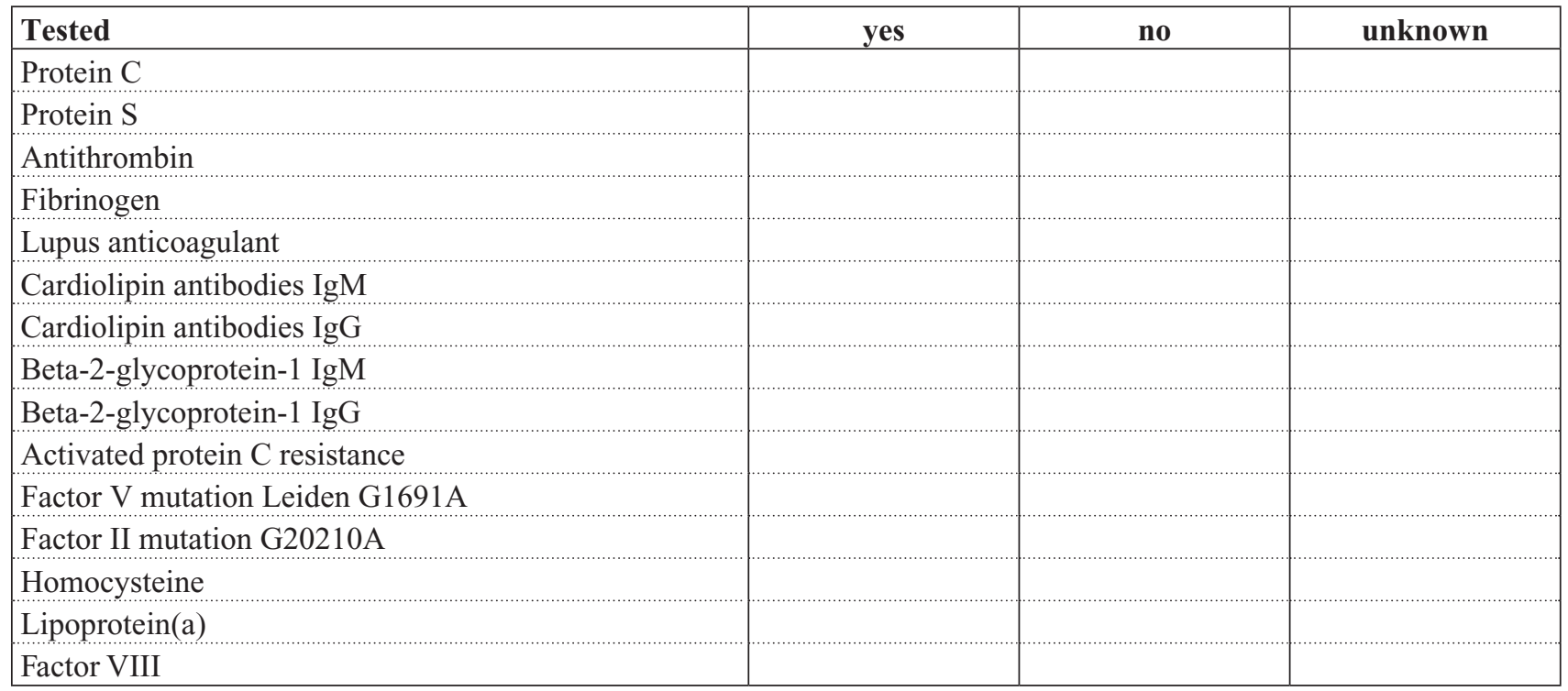

Documented defect: $\square$ yes $\square$ no $\square$ unknown

If yes, describe:

\section{Publish your work in this journal}

Clinical Epidemiology is an international, peer-reviewed, open access journal focusing on disease and drug epidemiology, identification of risk factors and screening procedures to develop optimal preventative initiatives and programs. Specific topics include: diagnosis, prognosis, treatment, screening, prevention, risk factor modification, systematic

Submit your manuscript here: http://www.dovepress.com/clinical-epidemiology-journal reviews, risk \& safety of medical interventions, epidemiology \& biostatical methods, evaluation of guidelines, translational medicine, health policies \& economic evaluations. The manuscript management system is completely online and includes a very quick and fair peerreview system, which is all easy to use. 